\title{
Knowledge flows in the form of entanglement and 'cuts': an agential realist perspective on knowledge construction phenomena within an aircraft manufacturing workplace
}

\author{
W. David Holford \\ University of Quebec at Montreal (UQAM) \\ holford.w_david@uqam.ca
}

\begin{abstract}
Organizational knowledge varies from explicit possessions to more tacit and sticky actions. As such, we argue that the entwined nature of tacit and explicit knowledge, the embodied and activity-based dimension of knowledge, as well as the characteristic of knowledge as possession, fit within an agential realist concept of phenomena, entanglement and 'cuts'. We first validate the framework across a qualitative case study within an aerospace manufacturing context. Our findings also provide insights on the nature/dynamics of novice to expert level knowledge. The implications on knowledge management are briefly discussed.
\end{abstract}

\section{Introduction}

Knowledge flows within and between organizational workgroups involve interacting individuals ranging from novice to expert level competencies and skills [1]. While novice levels are often attributed to knowledge that is relatively easy to explicate [2, 3], expert knowledge is more often associated to dynamic skills and competencies that are harder to fully explicate, such as Collins'[2] collective knowledge, Leonard and Swap's [4] deep smarts or Weick's [4] ready-to-hand mode of engaging in the world. As such, knowledge varies from fully explicit possessions to deeply tacit actions or activities [5].

More recent organization studies literature has placed much emphasis on knowledge as activity, or as an emergent flow (ie. knowing) [6]. In parallel, has been the evolving argument of knowledge's increasing 'stickiness' or entangled nature when going from know-that to know-how [7]. Yet key authors [8, 9] who have provided pertinent arguments for a hybridized, entangled, processual view of the world, are also the same authors we can draw upon to synthesize with its anti-thesis, that is, of socially constructed categories and non-representational interpretations as being also part of the overall complexity of organizations [10]. In applying the full expression of agential realism [8], that is of entanglement and 'cuts', we rejoin Cook and Brown's [5] dialectical concept of knowledge as both entangled activity and discrete possessions.

In the following paper, we first justify how the trifold aspects of the entwined nature of tacit and explicit knowledge, the embodied and activity-based dimension of knowledge, and the knowledge-aspossession characteristic of knowledge fit within Barad's [8] agential realist approach of phenomena, entanglement and 'cuts'. We then validate the proposed agential realist framework across empirical data collected from specific workgroups within an aerospace manufacturing context. A qualitative phenomenological methodology also allows us to better understand the nature/dynamics of novice to expert levels of knowledge. Finally, implications on knowledge management strategy are briefly discussed.

\section{Explicit-tacit knowledge entanglement}

The representational view of explicit knowledge is of a stable, universal and objective entity [11]. Explicit knowledge is seen as being expressed in formalised verbal or written words, and numbers, can be shared as data, scientific formulae, and so forth, whereby it assumes a semiotic ("fixed") aspect of language.

Yet explicit knowledge also contains nonrepresentational or contextual and interpretative aspects (e.g. interpretative ethnographic texts [12]; text as discourse and fiction [13]; and more fundamentally, the very nature of the interpretative/contextual semantic aspects of language [14]). Knowledge involves subjective constructions $[15,16]$. As such, Glasersfeld [15] addresses the representational claim of observer objectivity by explaining how human activity involves both the construction of action and symbolic interpretative semantic schemes leading towards sensorimotor and conceptual knowledge, respectively. "Each of these schemes is constructed based on unique personal experiences, which may be similar, but never 
identical to, another person's constructions" [15, p. 158]. Similarly, Collins' [2] argues that both somatic and collective tacit knowledge can only be partially explicated, in expressing out loud what we believe or interpret to be the explicit forms of tacit knowledge. Hence, both explicit and tacit knowledge, become part of a complexity that goes beyond a purely representational view of the world, in that we must consider the interpretations of complex systems in themselves [10], as well as the subsequent enactments these interpretations produce [17].

Polanyi's [18] concept of all knowledge being rooted in tacit knowledge provides a first glimpse of entanglement between tacit and explicit knowledge. According to Polanyi [18, p. 87], tacit skills are cooperating with the explicit, whereby the explicit involves symbolic representations that is part of a language that is created by articulation. The tacit, on the other hand, is knowledge that cannot be articulated in terms of the symbols of a language. Yet, the very meaning of these symbols rely partially on the tacit. To understand the most formalized sentences, a person is needed [18, p. 139-141]. Hence, not only is tacit knowledge entangled within a person, tacit and explicit knowledge are entangled to one-another.

\subsection{The incommensurability of tacit knowledge}

While it is argued that tacit and explicit knowledge are entangled to one another, tacit knowledge is incommensurable to explicit knowledge, in that:

a. Knowledge possessed and carried out by experts in the form of tacit knowledge cannot be fully expressed as language or code [2, 19]

b. Aspects that can be explicated may have little to do with the original tacit knowledge (ex. equations used as equivalent, yet not identical knowledge to represent the act of riding a bicycle [20]

Furthermore, capturing tacit knowledge across mere documentation and/or codification becomes problematic when considering: 1) the questionable assumption of tacit to explicit knowledge 'conversion' in the sense of rendering all tacit knowledge explicit in an identical and representational form [2, 16, 19]; 2) that the highly embodied nature of both collective and somatic tacit knowledge cannot be fully extracted by a simple act of disembodiment whether by language or codification [2]; and 3) contrary to explicit knowledge, the highly personal indwelling and contextualized nature of tacit knowledge renders its reversibility (via reproducibility and standardization) impossible [21].

\section{The embodied, activity-oriented nature of knowledge across agential realism}

The overall entangled nature of knowledge (between the explicit, the tacit and the individual) leads us towards the embodied nature of knowledge, and more specifically, two key features: that is, of integration within the body and that of action. Furthermore, the notion of embodied knowledge can be associated with the phenomenology of MerleauPonty [21]. In experiences of bodies in situations it is impossible to disentangle 'natural' and 'social' elements: "everything is both manufactured and natural in man, as it were, in the sense that there is not a word, not a form of behaviour which does not owe something to purely biological being" [21, p. 189]. The non-dual relationship between the natural and the manufactured, as well as the human and the non-human, is again taken up by more recent literature on socio-materiality "there is no social that is not also material, and no material that is not also social" [6, p. 29]. Orlikowski's socio-materiality is based on an epistemology (or ontoepistemology) which defines and describes the role and importance of phenomenon within everyday reality known as agential realism. Here, reality is viewed as a collection of phenomena involving the intra-action between agencies of observation and 'objects' [8]. Phenomena represent the inseparability of an object and observations of it. It also connotes a dynamic quality, and thus, in combination with agency, implies action. Central to scientific practices, is "that knowing does not come from standing at a distance and representing but rather from a direct material engagement with the world" [8, p. 49]. As Barad [8, p. 157] points out, “....we do not see merely with our eyes. Interacting with $[\ldots]$ the world is part and parcel of seeing. Objects are not already there; they emerge through specific practices". Furthermore, "whereas the construct of interaction suggests two entities, given in advance, that come together and engage in some kind of exchange, intra-action underscores the sense in which subjects and objects emerge through their encounters with each other" [22, p.267].

\subsection{Agential realism and knowledge-as- possession}

Despite the non-representional arguments (sections 2) on viewing explicit knowledge as interpretable (re)constructions, and that these constructions are entangled with tacit knowledge, language (or code) in itself has an artefactual aspect [23]. Language as an artefact provides a mark or trace. Yet, the sense or meaning we assign to it can no longer be viewed as 
universal and objective. Utterances are personal and reconstructed all the time [23]. But despite its subjective and changing nature, it nevertheless provides an opportunity for us to possess our own meaning - for as we make sense of the world, we bracket our attention from the continuous flow [15, p. 90-91, 24]. We thus rejoin an epistemology of possession [5], but with a non-representational twist to it. Capturing such nonrepresentational and contextually specific semantic complexities can nonetheless be achieved, for example, across semiotic mediation [10, p. 776-777].

According to Barad [8], the deeply connected way that everything is entangled with everything else means that any act of observation makes a "cut" between what is included and excluded from what is being considered. This cut is an interpretive and subjective act which depends on context, points of views and apparatus configurations at hand. Throughout the complexity of enactment and agency, boundaries or cuts are not given but constructed [16]. Thus, agential realism embraces knowledge-as-construction in the sense of temporary end-results or possessions.

Agential realism acknowledges the role of language and discourse in the construction of reality [8]. Yet, a discursive reality is only one of the realities that can be observed. Matter as phenomena of different orders intra-act with each other and provide different levels of affections. It is why, across agential realism, we can embrace knowledge both as an activity (as intra-acting agents) and as a possession (in the form of 'cuts').

\section{Research aim and methodology}

This research sought to determine the validity of an agential realist framework of knowledge-as-activity and knowledge-as-possession in relation to how knowledge is constructed within a large North American aircraft manufacturing company (over 8000 people worldwide). Our initial starting point was at the level of the workgroup environment. Here, we had the opportunity to study knowledge flow phenomena in the form of entanglement and 'cuts' within and across two work groups.

\subsection{The EOD and ECRT workgroups}

The Engine Operability Development or EOD group (5 members) is responsible for ensuring the development of adequate engine operability envelopes throughout all phases of engine development programs. The proper establishment of the engine operability envelope is of critical importance, in that it delimits the boundaries beyond which the aircraft risks running into critical compressor surges or other types of catastrophic engine failures. A principal objective of the EOD group is to ensure meaningful engine component test data is generated. Establishing the type of engine test data to be generated is negotiated between the EOD group and the Engine Component Rig Testing (ECRT) group (8 members); the latter being responsible for the generating and integrity of the required engine component test data. In turn, the ECTR group's responsibilities include the development and preparation of component test rigs (required for each new engine development program), their subsequent test runs, and the proper collection of test data. Both groups interact with each other daily.

\subsection{Data collection and analysis}

According to Hycner [24, p. 156] "the phenomenon dictates the method". The phenomena of interest focused on intra-actions within and across two of these work groups (EOD and ECTR) within the firm. As such, a phenomenological approach was adopted across a qualitative ethnographic case study using direct observations and interviews. Interviews were either semi-structured or ad hoc. According to Bailey $[25$, p. 72] the "informal interview is a conscious attempt by the researcher to find out more information about the setting of the person". The qualitative interview "is literally an inter view, an interchange of views between two persons conversing about a theme of mutual interest," where the researcher attempts to "understand the world from the subjects' point of view, to unfold meaning of peoples' experiences" [26, p. 12]. Furthermore, "doing phenomenology" means capturing "rich descriptions of phenomena and their settings" to allow the essence to emerge [27, p. 104].

The primary research design criterion sought was based on trustworthiness [28], involving the constructivist sub-criteria of: i) credibility via both the saturation of findings and triangulation of data collection to obtain complementary perspectives. Also in support of this primary criterion of trustworthiness, was our desire to attain reliability of data by ensuring that the research was conducted "as if someone were looking over our shoulder" [29, p. 38]; that is, making sure we had rigorous documentation of data so as to provide an adequate audit trail.

We were also able to collect data from video of specific meeting interactions. We remained on the 'look-out' for cues (such as voice tonality, facial expressions, body language, etc.) bringing forth important contextual information [30]. Attention was especially placed on interpreting the data for semiotic significance. On this latter point, we borrowed from Aktouf [31, p. 419], whereby "without pretending to any particular specialisation", relied on our own 
theoretical, intellectual and professional experience in attempting to link and synthesize different discourses. While keeping an 'alert eye' out for the linguistic terms used, the nature of the data collected allowed us to listen, view and analyze digitally recorded transcriptions, hand-written notes and captured video for insights into both verbal and non-verbal communications used between participants.

\section{Results}

\subsection{The ECRT group:}

Group members were seated in an open space environment and often discussed various technical issues with one another for possible solutions.

Technical discussions were often accompanied with the act of sketching a specific view of a rig or engine component in question. Various cues were observed indicating understanding, questioning or disagreement across words such as "Yep", "Oh really? I thought the chamfer had a smoother profile than that..." and "No, the airfoil cooling hole needs to be drilled at 45 degrees...". Similar exchanges occurred with the use of pre-existing 2D drawing cross-sections - usually modified with pen/pencil to explain one's perspective, understand someone else's perspective or construct new perspectives.

One such exchange occurred between two members (Lloyd and Robert) and the manager (Richard) in regards to a rig set-up. Richard appears to be thinking out-loud in regards to a torque measurement test that will involve significant modifications:

Richard: "I think we'll need to change the torque shaft and replace it with a smaller one since the readings we're trying to pick up are extremely small..."

Robert replies while simultaneously drawing the following schematic of a torque shaft:

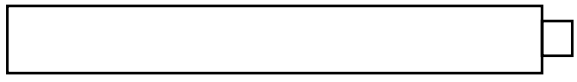

Robert: "We already know the total inertia of the assembly..."

Robert then points to the right extremity of the shaft and adds:

Robert: “...so by placing a sensor here, we should get a good idea of what's going on."

Richard responds by pointing to the middle shaft area Robert has drawn, and adds his own lines in the same vicinity representing a bearing shroud along with arrows representing noise and vibrations, while saying:

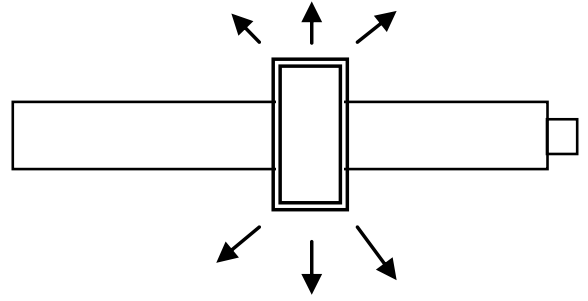

Richard: "Ya, but what about the noise and vibrations coming from the bearing shroud?"

While Robert ponders over this, Lloyd whose been listening all this time goes to the board and draws a heavy arrow going across the top of the bearing shroud and starts saying:

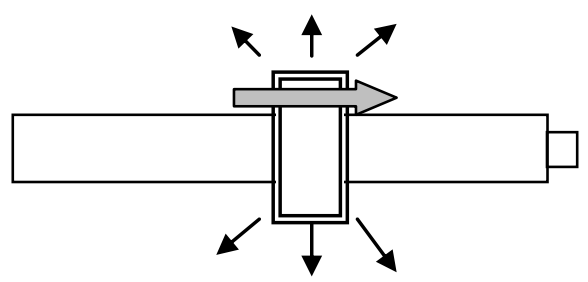

Lloyd: "Well, if your main transient vibrations are going this way..."

Lloyd then adds two vertical lines while finishing his statement:

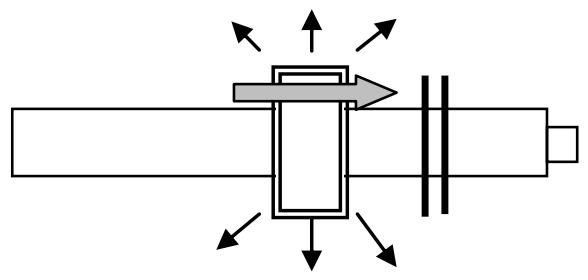

Lloyd: “...you can add a spacer ring over here."

With Lloyd's last contribution a consensus is reached amongst all three members. Yet it took each member's contribution to bring about a better understanding of the situation. What is important to note in the above example is the step by step or incremental progression of both verbal and visual aspects of an evolving narrative. Complementing the actual action of drawing was the frequent use of hand/arm movement to explain particular aspects of the torque shaft assembly.

\subsection{EOD-ECTR intra-actions:}

The EOD-ECRT inter-actions involved technical discussions that were again often accompanied by 
active sketching or pointing to various visual aids (such as 2-D drawings, computer screens, 3-D models).

An example of intra-actions between the two groups was in relation to the torque shaft assembly that had been previously discussed between Lloyd, Robert and Richard, which Allan from the EOD group now has a chance to discuss with both Richard and Robert, while looking at the basic torque shaft sketch. Allan, as an expert in compressors, is well respected by all.

Allan: "Like the idea of the spacer ring... what I'm scared is we won't be able to measure transients coming from the upstream compressor."

As he says this, his index finger points to the spacer ring, and then traces back the extreme left (upstream) to where the eventual compressor rotor will be.

Richard: "Why do you need this?"

Allan: (while pointing at the imaginary compressor rotor area) "Design are pushing the ratios...we may have vibration problems."

Robert: "On the shaft?" (traces his index finger from middle of shaft towards extreme right).

Allan: (while pointing at imaginary compressor rotor area on extreme left) "Ya...because of flutter on the blades"

Robert: "What about pressure paint?" (points finger at Allan's imaginary compressor rotor area).

Allan: "Pressure paint could do... but then we may need two tests... This one with pressure paint... and if the pressure paint confirms the flutter then we gotta get rid of the spacer and put in the right shaft on a dime."

Richard: "But if you confirm flutter why the shaft measurements?" (now pointing downstream along the shaft)

Allan: "Management want this...if anything looks screwy, I'll need the shaft measurements to convince them one way or the other".

Richard: "What's your feeling?"

Allan: "They're tweeking the models...physical tests and 'thumbs' tell me it's trouble...but I don't know. It's too close...I wouldn't bet $\mathrm{s}^{* * *}$... They know that...We're promising too much."

Richard: "Okay... We'll change the shaft...and get all the data....(now looks at Robert)...What do you think ?"

Robert: (Nodding) "Uh huh..."

Allan is highly regarded by both the members of the EOD and ECTR groups. Two years earlier the company had awarded him the highest technical title it reserved to outstanding experts in their respective fields - that of Senior Fellow. Richard knows that Allan's worries are founded on his vast technical knowledge of compressor aerodynamics. Hence, the basic torque shaft configuration agreed upon earlier on between Lloyd, Robert and Richard would eventually be changed to what Richard first had in mind (despite an additional 10 day delay); that is, a test rig with a more robust and representative torque shaft resembling engine configurations, with no spacer ring. The sensors that Robert had proposed at the right end of the torque shaft would remain however, so as to detect any vibrations caused by possible upstream compressor 'flutter' (compressor blade vibration modes with negative consequences on performance of the engine).

\subsection{On becoming an expert according to Allan and Frank:}

Across informal conversations, both Allan and Frank had talked about the type of knowledge that was important to obtain to attain a high level of expertise in their respective domains. Both Alan and Frank conducted engine rig coordination in the EOD group. Frank had spent a good deal of his career as a project engineer. Alan had also done a stint in Project Engineering coordinating engine development programs, but his core expertise was as a specialistexpert in compressor aerodynamics.

Frank had first spoken to me about how it was important for engineers to go and see the engine running - on how one needed to "feel the engine". He was passionate in explaining "the engine breeeathes", since to him one had to "liiiiive the engine"! He explained how when speaking to someone in regards to a turbine section of the engine, he would actually visualize the rotor and blades rotating within the engine, and how a change in gas flow would affect the mechanical and aerodynamic behavior of the turbine blades in question. Hands-on experience was primordial in gaining expertise trouble-shooting, which in his own words, "allowed me, over time, to establish rules-of-thumb important for specific situations".

In a similar manner, Allan also felt that many engineers, while being very proficient in using computer models, needed to go out and see how engines behaved. Allan explained that on one occasion he was looking at a model prediction and first reacted to the younger engineer "there's something wrong with that solution". On that particular occasion, he remembered how he couldn't yet explain how the algorithm needed to be modified, but was able to offer a partial explanation to the junior engineer with a specific rule-of-thumb that needed to be kept in mind for that particular mode of operation. Subsequent engine tests proved him right. One of Allan's concerns is that "the digital engine is keeping a lot of engineers in front of their screens. They've got to go and feel the engine. I'm not sure how tomorrow's experts will be able to deal with problems without doing that".

Mark, a junior engineer, speaks with a great deal of respect in regards to Allan: "Allan is easy to talk to, and he likes it when I debate with him...he'll challenge me on stuff, and I challenge him on stuff...The real life engine is important, and I've come to learn how he can 
pick out early signals...His experience and thinking makes him come up with 'thumbs'...I've seen him solve the Russian pipe diffuser test that seemed completely different from ours... Everyone thought we needed to change our design, but he looked at the tests and saw it was all to do with temperature measurements...He'll also bring up 'thumbs' I never knew existed. I mean, he's created some of them".

\section{Analysis of results}

\subsection{Phenomena as intra-acting agencies via boundary constructions}

The above results showed different dialogical exchanges involving human and non-human entities. For example, in the ECTR group, members acted as agents who influenced one another, as seen across the dialogical interchanges. Within those interchanges were also numerous non-human influences, as seen for example from the visual and concrete sketch which emerged between Lloyd, Robert and Richard in regards to possible conceptions for a torque-shaft rig test. Here, two intertwining non-human entities can be identified: a) the concrete sketch or hand-made drawing, and b) the abstract concepts as represented by the sketch. The reciprocal influences between human (group members) and non-human (boundary objects under construction as sketches and epistemic conceptions) entities are provided by both interpretation of the objects under construction $[15,32]$ and enactment upon the objects as a result of interpretation [32], thereby leading us to the conception of dynamic boundary constructions [33] which is viewed as an emergent process of interinfluences. In a similar way we can describe both the EOD and ECTR-EOD strands as involving both human (group members) and non-human (sketches, computer screens, concepts, etc.) agents which again interinfluence one-another. Mark from the EOD group explains on the act of drawing:

"It's as if you're constructing it - not concretely in mechanical terms, since it's more in a 'virtual' sense, but it's a lot more than just words. For example when I say 'We got to change this' - if you haven't seen it then you're wondering 'Change what?'... So by making a drawing I feel it makes the idea in your head come out for everyone to see - and have everyone better understand or feel your own experience...And that's how people can then say to you 'Ah that's what you meant. Well, in that case, no I don't think that's feasible...or ya, I think that can be done."'

This act of drawing is accompanied by sensemaking and interpretation [15]. But Goodwin [34] also speaks of the "symbiotic" relationship between gestures and their objects, whereby the gesture's objects are integral components of the gesture itself. Hence, it becomes tricky to define the clear cut boundaries between the bodies and the gesturing. Not only are the contents of the bodies changing with time (in terms of the changing form of the artefact as well as the increasing comprehension achieved by the subject), but the boundaries themselves seem to shift or become blurred. The integral whole (gesture, actor and object) becomes more easily understood as a phenomenon.

\subsection{A phenomenological view of tacit and explicit knowledge entanglement}

Embedded within the boundary construction process described above is the entanglement of tacit and explicit knowledge. As members re-constructed meaning across both dialogue and visual artefacts, language intertwined with visual representations.

Language itself carries a tacit dimension: the ability to recognize/deploy the right word at the right time goes beyond the limits of what can be codified [2].

Furthermore, the visual construction and reconstruction of artefacts as boundary constructions carries a tacit aspect that words alone would have a great deal of difficulty describing completely [35]. In both cases of static or dynamically changing images, the bodily senses are activated towards an act of embodiment, whereby we are constantly attempting to correspond formal representations to the experiences of our senses [19]. Words uttered were often accompanied by manipulations of existing objects and acts of drawing. Dialogue in itself can be viewed as a specific form of intra-active practice - or as Shotter [36, p. 7] states: 'an unceasing flow of language intratwined activities...As a consequence...in being spontaneously responsive to each other in the course of our acting, we act jointly or dialogically...Uniquely new understandings, appropriate to the circumstances of their occurrence, are continually created within it... they emerge, and the entangled nature of the process of their production cannot easily be untangled'.

Across a phenomenological perspective - whereby "all knowing involves skillful action and that the knower necessarily participates in all acts of understanding" [37, p. 457], one can depict how tacit and explicit knowledge are entangled in varying degrees depending on the situation at hand.

Firstly, there is what is known as absorbed or practical coping [38]: here, actors are subsidiarily aware of their knowing and practising, without being self-aware. One is engaged within a practical context across spontaneous actions and responses to a given task. Absorbed or practical coping is where people deal with their context in a holistic and inter-related fashion 
which calls "for direct skillful handling" involving "tacit knowledge" [3, p. 73-76]. Absorbed coping is where people deal with their context in a holistic and inter-related fashion which seniors or experts in their respective domains are more likely to detain than beginners, which calls for direct skillful handling involving tacit knowledge [3, 39]. This first mode thus involves a good deal of tacit knowledge. This first mode can be associated for example to ECTR members working on CAD-CAM models on computer screens, whereby different screen views were brought forward and then made to disappear in an ongoing fluid manner that seemed second natured; while in similar fashion, EOD members brought up, modified and manipulated various computer screen views of thermodynamic envelopes towards the preparation of test protocols for a given test rig, all of this in rapid succession.

A second mode is known as on mindful coping [38]: it is where "reflective knowledge is generated in the midst of action, in dialogue with a developing situation at hand...unlike in the case of practical coping, practitioners cannot rely on their nondeliberate, intuitive mode of acting because something unusual has happened (a breakdown) on which they need to reflect...practitioners draw on their contextbased, intuitive understanding, but check and refine it to deal with the problematic situation" [39, p. 399]. It is where problematic aspects of a situation stand-out yet also where 'people still do not become aware of context-free objects nor do they report feelings of overload' [3, p. 73]. This was seen across numerous examples of dialogical exchanges within both the EOD or ECTR groups. For example, Lloyd, Robert and Richard when discussing and eventually generating a possible torque shaft rig test configuration. All three members were drawing knowledge from one another, always within the context at hand, to eventually generate and agree upon a sketched solution in regards to the thin and potentially too flexible, torque shaft at hand. Ideas (addition of sensor at end of shaft; use of spacer disc) drew upon members' (Robert and Lloyd) past experiences within the context of rig testing. In a more general sense, experts such as Allan or Frank in the EOD group use this mode quite often when dealing with problems at hand. Both described how they use inferential relations grounded and embedded in practical as well as grounded theoretical knowledge (which they refer to as rules of thumbs). Here, knowhow concepts are applied to situational contexts, whereby the process of abduction is used in which single events are linked to the tacit knowing of "family resemblance" between those events [40, p. 133]. Abduction combines logical reasoning, aesthetic judgement (the hypothesis must be 'elegant') and prereflexive moves (Peirce speaks of 'flashes') - in other words, it mixes intuition and reasoning [10]. Hence, this second mode involves certain aspects of knowledge that is explicated - while other key aspects still remain very difficult to fully explicate (deep tacit).

A final mode is known as detached coping [38] (or 'present-at-hand' mode) involves a temporary stoppage of activity whereby individuals stop all normal ongoing activities to detach themselves from the activityat-hand and begin to reflect in more abstract and theoretical terms (often with the help of outside repositories of knowledge, such as textbooks or manuals, or other individuals not involved in the practice-at-hand yet knowledgeable in abstract decontextualized knowledge). It is a mode where practitioners have insufficient knowledge within the context at hand and must temporarily tap into external sources of abstract knowledge for possible inspirations [3]. Here, participants emphasize focal awareness across retrospection as to the nature of the practices involved, and attempt to reduce equivocal manners of interpretations across the acquisition of external abstract knowledge [38]. This mode seemed to fit extremely well with a situation I was able to discuss with Allan at length - that is, of the Russian pipe diffuser dilemma. Engineers seemed at a loss to explain why a Russian pipe diffuser behaved so differently from the company's own design. Allan recalls the many nights he had poured over the Russian test report in comparison with a half dozen tests conducted on in-house designs. He also remembers having spent a great deal of time going over test protocol manuals to ensure no erroneous assumptions had been made in regards to test procedures. As an aerodynamics specialist, he admitted that he was not as cognizant in temperature probe locations and constraints as was Richard from the ECTR. He explained how he had called Richard five times before finally understanding what test conditions had been used versus what should have been used. He eventually came to understand (with the help of Richard from ECTR) that insufficient thermocouples had been used in a specific, yet obscure part of the engine. The test comparison between the Russian and in-house pipe diffuser became tantamount to comparing apples and oranges. In general, and as can be seen in this example, this third mode of heideggerian coping involves a good deal of explicated (explicit) knowledge.

\subsection{The on-going tension between ever- changing entanglements and 'cuts'}

As soon as we utter an articulation, we interpret (or produce a 'cut'). Furthermore, dialogue can be viewed as ever-changing cuts or interpretations: "although 
there are real unitary components in the entangled, stranded, unfolding processes at work in the production of our utterances, they are not units fixed for all time, that we can transport into another context for a closer examination; although real, they are transitory units, existing only as dynamic stabilities within the moment of their expression, i.e., their utterance" [36, p. 7]. An example of this was in regards to the torque shaft measuring test involving two separate series of dialogical exchange: the first within the ECTR group between Lloyd, Robert and Richard, and the second in the EOD-ECTR context involving both Allan and Richard. The first series of exchanges led to an agreed upon test rig configuration. But this configuration was brought back into question by Allan in the second series of exchanges this time involving both Richard and Allan. Both Allan and Richard eventually decided that the configuration solution to be tested out would be a hybrid between what Richard had first thought at the beginning of the first exchange (the use of a more robust torque shaft) and what Robert had subsequently proposed (putting a sensor at the end of the torque shaft). We can view these two series of dialogical exchanges as two intra-mingling strands, whereby one affected the other. We can also paraphrase Shotter's [36, p. 4] view of agential realism involving an "unfolding world of stranded, intra-mingling flowing processes, each with their own agentive powers". Cuts are made, yet remain temporary, whereby new cuts are made depending on the unfolding context at hand to modify past interpretations (or cuts) in an everchanging process - thus rejoining the dialectic of knowledge as both activity and possession [5].

\section{Agential realism and its implications for knowledge management}

We argue that agential realism offers the opportunity for individuals (or groups) who possess and act out embodied tacit knowledge to continue to do so in the presence of communication and information technology, with the latter acting as enhancers of tacit knowledge creation and sharing within the groups or individuals in question [41].

Within our own results, boundary constructions as phenomenon-in-progress show humans and nonhumans (in the form of concrete and conceptual objects) influencing one another. Along these lines, Brangier et al [42] explains the symbiotic relationship between technology and the social whose main aim is for the successful outcome a technical project, whereby neither technical or human preoccupations dominates one or the other. Across a co-evolutive relationship, humans and technology shape each other mutually within a relationship of reciprocal symbiotic dependency. The primary aim, according to Brangier et al [42], is to use the best of humans and the best of machines to improve human intellectual capacity.

In a similar manner, across boundary construction phenomena, we view knowledge as embodied within a total configuration - whereby technology becomes an extension of humans, producing a blurred boundary between humans and technology, and whereby cuts or boundary to be made depend on context, interpretation and configurations at hand [8]. This rejoins Suchman's [22] work on Human-Machine Reconfigurations. 'Deep', 'sticky' tacit knowledge can remain tacit without attempting to be fully articulated or disembodied at the expense of knowledge impoverishment [2, 19]. Yet, tacit knowledge can still be shared across mentoring, imitation or doing [2].

Artificial intelligence (AI) has in the last few years taken a very active interest in the role of abduction in an attempt to reproduce human creativity [44]. More specifically, AI has attempted to dissect out the human abductive process through a series of statistically derived algorithmic steps, which according to Patokorpi [43, p. 123], is quite different from the more holistic character of human abduction which involves a good deal of perception-based reasoning which retains a connection to meaning 'because percepts make sense to us... In other words, perception is inferential by nature'. The former is a logical homologous representation which 'entails interfering with the phenomenon through complicated data massaging' which becomes a form of truncation of the phenomena in question [43, p.124; 21]. As such, the intuitive aspect of abduction remains highly ubiquitous. In an similar manner, the phenomenological study of creativity highlights its paradoxical nature [44] - in trying to model creativity, we impose rules and generalities, keeping in mind creativity abhors rules in the first place. The end-result is that in trying to capture creativity by choosing and setting variables associated to it, it dissipates within our hands [44].

Conversely, agential realism is a holistic approach able to embrace the irreducible, embodied and action oriented nature of expert tacit knowledge generated and shared between individuals within organizations in the presence of technology. Technology becomes an extension of the human senses and bodily movements in both a real and virtual sense (ex. simulators). As such, agential realism allows us to combine AI's strength which relies on knowledge dissection and explication (i.e. pure 'cuts') when elaborate calculations are called upon, in combination with the strengths of humans, involving entangled tacit-explicit knowledge carried and generated via creative strategies such as abduction (i.e. 'cuts' plus entanglement). 
Hence, not only can machines free up humans for what they do best - that is, the act of creating, but humans working together with machines can be used to outperform machines or humans alone [45].

\section{Conclusion}

An agential realist approach [9] allows us to fully capture both knowledge-as-process and knowledge-asentity, thus rejoining Cook and Brown's [5] dialectic epistemology of activity and possession. Our empirical findings attempted to validate this. Boundary construction phenomenon was a key process helping us to depict knowledge entanglement (tacit and explicit) across dialogue and non-verbal actions. Boundary constructions also depicted the intra-action (or agency) between human/non-human entities. Dialogue also brought forth the aspect of knowledge as interpretations or 'cuts'. And finally, a phenomenological analysis allowed us to describe certain coping strategies associated to various levels of knowledge expertise - ranging from absorbed and mindful coping with respect to higher knowledge expertise to detached coping with respect to lower levels of knowledge expertise. Of particular interest was the identification of specific tacit/explicit heuristics carried out by knowledge experts, often in the form of abduction (i.e. leading to rules-of-thumb).

The deeply entwined nature of tacit and explicit knowledge within technical experts seems to accompany their creative capabilities. As such, KM strategies to help further enhance expert creativity should be considered. One promising avenue is the post-humanist approach of human-machine interactions allowing for technologies such as AI to free up humans to concentrate on creative work. Conversely, the entangled and phenomenological nature of expert knowledge depicted in this paper tends to reinforce the argument against using AI to replace human creativity via knowledge dissection and/or knowledge mimicking strategies.

It is acknowledged that the relatively narrow context of our empirical work limits our ability to generalize our findings and arguments.

\section{References}

[1] M. Wilkesmane, and U. Wilkesmane, "Knowledge transfer as interaction between experts and novices supported by technology", The Journal of Information and Knowledge Management Systems, 2011, 41(2), pp. 96-112.

[2] Collins, H., Tacit and Explicit Knowledge, University of Chicago Press, Chicago, 2010.
[3] Weick, K., Making Sense of the Organization (Volume 2): The Impermanent Organization, John Wiley and Sons, West Sussex, UK., 2009.

[4] D. Leonard, and W. Swap W, "Deep Smarts", Harvard Business Review, 30:2, 2004, pp. 157-169.

[5] S. Cook, and J.S. Brown, "Bridging Epistemologies: The Generative Dance Between Organizational Knowledge and Organizational Knowing, Organization Science, 1999, 10(4), pp. 381-400.

[6] W.J. Orlikowski, "Sociomaterial practices: exploring technology at work", Organization Studies, 2007, 28(9), pp. $1435-1448$.

[7] W. Kupers, "Embodied "inter-learning" -an integral phenomenology of learning in and by organizations", The Learning Organization, 2008, 15(5), pp. 388-408.

[8] Barad, K., Meeting the Universe Halfway: Quantum Physics and the Entanglement of Matter and Meaning, Duke University Press, Durham, NC, 2007.

[9] Latour, B., We Have Never Been Modern, Harvard University Press, Cambridge, MA, 1993.

[10] P. Lorino, B. Tricard and Y. Clot, "Research methods for non-representational approaches to organizational complexity: the dialogical mediated inquiry", Organization Studies, 2011, 32(6), pp. 769-801.

[11] G. Szulanski, "The process of knowledge transfer: A diachronic analysis of stickiness", Organizational Behavior and Human Decision Processes, 2000, 82(1), pp. 9-27.

[12] G. Geertz, "La description dense. Vers une théorie interprétative de la culture", Enquêtes, 1998, 6, pp. 73-105.

[13] T. Watson, "Ethnographic fiction science: making sense of managerial work and organizational research processes with Caroline and Terry", Organization, 2000, 7(3), pp, 489510.

[14] Benvéniste, E., Problèmes de linguistique générale, Volume 2, Gallimard, Paris, 1980.

[15] Glasersfeld, E. von, Radical Constructivism: A Way of Knowing and Learning, RoutledgeFalmer, London, 2002.

[16] Virtanen, I. "In Search for a Theoretically Firmer Epistemological Foundation for the Relationship Between Tacit and Explicit Knowledge", The Electronic Journal of Knowledge Management, 2013, 11(2), pp118-126.

[17] W.J. Orlikowski, , "Knowing in practice: enacting a collective capability in distributed organizing", Organization Science, 2000, 13(3), pp. 249-273.

[18] Polanyi, M., Personal Knowledge, Chicago: The University of Chicago Press, 1962. 
[19] Tsoukas, H., "Do we really understand tacit knowledge" in M. Easterby-Smith \& M. Lyles (eds), The Blackwell Handbook of Organizational Learning and Knowledge Management, Blackwell, 2003, pp. 410-427.

[20] R. Ribeiro, and H. Collins, "The bread-making machine: tacit knowledge and two types of action", Organization Studies, 2007, 28(9), pp. 1417-1433.

[21] Merleau-Ponty, M. Trans: Colin Smith. Phenomenology of Perception, London: Routledge \& Kegan Paul, 1962.

[22] L.A. Suchman, Human-Machine Reconfigurations: Plans and Situated Actions, Cambridge University Press, Cambridge, 2009.

[23] H. Tsoukas, "A dialogical approach to the creation of new knowledge in organizations", Organization science, 2009, 20(6), pp. 941-953.

[24] R.H. Hycner, "Some guidelines for the phenomenological analysis of interview data, in A. Bryman and R.G. Burgess (Eds), Qualitative Research, Vol. 3, pp. 143-164, Sage, London, 1999.

[25] Bailey, CA, A Guide to Field Research, Pine Forge, Thousand Oaks, CA, 1996.

[26] Kvale, S., Interviews: An introduction to qualitative research interviewing, Sage, Thousand Oaks, CA, 1996.

[27] D.A. Kensit, "Rogerian theory: a critique of pure clientcentered therapy", Counseling Psychology Quarterly, 2000, 13(4), pp. 345-352

[28] Lincoln, Y.S. and E.G. Guba, Naturalistic Enquiry, Sage Publications, Newbury Park, CA, 1985.

[29] Yin, R.K., Case Study Research: Design and Method, $3^{\text {rd }}$ Edition, Journal, Sage Publ., Thousand Oaks, CA, 2003.

[30] M. Dickey, G. Burnett, K.M. Chudoba and M.M. Kasmer, "Do you read me? Perspective making and perspective taking in chat communities", Journal of the Association for Information Systems, 8(1), 2007, pp. 47-69.

[31] O. Aktouf, "Une approche observation participante des problèmes représentationnels, théoriques et épistémologiques liés aux aspects relationnels et organisationnels dans les rapports de travail", Ph.D. Dissertation, École des Hautes Études Commerciales (HEC Montréal) affillié à l'Université de Montréal, 1982, Montreal, Quebec, Canada.

[32] Weick, K., Sensemaking in Organizations, Sage Publications, Thousand Oaks, CA, 1995.
[33] W.D. Holford, "Boundary contructions as knowledge flows within and between workgroups", Knowledge Management Research and Practice, 2016, 14(1), pp. 4-14.

[34] C. Goodwinn, "The body in action. In Discourse, the Body and Identity", In Coupland, J. and Gwyn, R. (Eds), Palmgrave/MacMillan, pp. 19-42, New York, 2003.

[35] Gilbert, J.K., Constructing Worlds Through Science Education, Routledge, New York, 2005.

[36] J. Shotter, "Reflections on sociomateriality and dialogicality in organization studies: from 'inter-' to 'intrathinking' in performing practices", $3^{\text {rd }}$ International Symposium on Process Organization Studies, June 16-18, 2011, Corfu, pp. 1-14.

[37] H. Tsoukas, "How should we understand tacit knowledge? A phenomenological view", in M. EasterbySmith and M.A. Lyles (Eds), Handbook of Organizational Learning and Knowledge Management, pp. 453-476, John Wiley, London, 2015.

[38] A. Guiette and K. Vandenbempt, "Learning in times of dynamic complexity through balancing phenomenal qualities of sensemaking", Management Learning, 2016, 47(1), pp. 83-99.

[39] H. Tsoukas, "Strategic decision making and knowledge: a Heideggerian approach", in Nutt, P.C. and Wilson D.C., Handbook of Decision Making, pp. 379-402, John Wiley, London, 2010.

[40] Adloff, F., Gerund, K. and Kaldewey, D., Revealing Tacit Knowledge - Embodiment and Explication, DFG, Germany, 2015.

[41] Holford, W.D. and Hadaya, P. "Addressing the tacit knowledge gap in knowledge systems across agential realism", The $50^{\text {th }}$ Hawaii International Conference on System Sciences (HICSS-50), 2017, Waikoloa, Big Island, Hawaii, IEEE, Computer Society Press, pp. 4465-4474.

[42] Brangier, E., Dufresne, A., Hammes-Adelé, S. (2009) "Approche symbiotique de la relation humain-technologie: perspectives pour l'ergonomie informatique", Le travail humain, 72, pp. 333-353.

[43] E. Patokorpi, "What could abductive reasoning contribute to human computer interaction? A technology domestication view", PsychNology, 2009, 7(1), pp. 113-131.

[44] Seyidov, S., Phenomenology of Creativity, AuthorHouseUK, London, 2013.

[45] Kasparov, G., Deep Thinking: Where Machine Intelligence Ends and Human Creativity Begins, PublicAffairs, 2017. 